\title{
O DIREITO DAS MINORIAS E AS NAÇÕES INDÍGENAS NO BRASIL
}

\author{
Maria Stella Ferreira Levy*
}

\begin{abstract}
O presente artigo trata de questões da história, do direito, da economia, da antropologia, da sociologia, da política, no que tange a minorias, salientando alguns marcos significativos da política indigenista brasileira na década de 1980. No que tange aos direitos humanos aplicados às minorias, se anteriormente o fulcro era a proteção desses direitos, hoje se demanda a sua regulação e a garantia jurídica, fomentando uma reordenação dessas relações. Essa foi uma grande contribuição da Constituição de 1988 no que diz respeito às comunidades indígenas que habitam o território nacional.

PALAVRAS-CHAVE: minorias, povos indígenas, direitos constitucionais, direitos humanos, leis.
\end{abstract}

\section{O DIREITO DAS MINORIAS}

A problemática dos direitos das minorias tem suas origens na Europa com a Reforma, que quebra a dupla tutela - do Papa e do Imperador -, em um Estado ainda não unificado. Foram as normas diplomáticas, chamadas de "traité de cession territoriale", inscritas em uma lógica territorial das minorias religiosas, que tomaram a forma de acordo bilateral e expressaram a servidão territorial. Foi essa construção jurídica que preservou, no Estado, a integridade do príncipe de um lado, e, de outro, a unidade da fé.

Entre os súditos do príncipe, submetidos exclusivamente à sua legislação, da qual os estrangeiros não faziam parte, se inscreve uma nova categoria jurídica, as minorias, ou seja sujeitos dotados de um status particular. (Rouland, et al,1996, p.159).

* Doutora em Saúde Pública e em Direito Civil. Professora Associada do Departamento de Epidemiologia, Faculdade de Saúde Pública da USP.

Universidade de São Paulo, Faculdade de Saúde Pública, Departamento de Epidemiologia. Cep: 01246904 - Sao Paulo, SP - Brasil.msflevy@usp.br
O Tratado de Oliva, ${ }^{1}$ de 1660 , pôs fim à guerra entre Carlos X da Suécia e Jean Casimir, rei da Polônia, que litigavam sobre a Pomerânia, permitindo a liberdade religiosa e se esforçando para estabelecer um modus vivendi entre católicos e protestantes, habitantes de suas terras. Essa postura contribuiu para que, com influências das teorias do contrato social e político, e privilegiando a ideologia de que a religião reside totalmente na consciência individual de cada um, a liberdade religiosa fosse inserida em uma liberdade de consciência, cuja expressão máxima é a declaração dos direitos da Virgínia de 1776. Dessa liberdade de consciência decorrem os movimentos nacionais, uma vez que, ao alvorecer do século XIX, essa sociedade política se encarna na do cidadão - todos somos indivíduos iguais.

Essas posições evoluíram para o princípio

\footnotetext{
1 Aqui são resumidos os capítulos da seção I - La Constituition des minorités par le droit des gens, p. 158166. Segundo os autores, até o Congresso de Viena de 1815, foram realizados sete tipos desses tratados. Entre outros, o de Nimègue (1678), entre a França e a Holanda; o de Breslau (1742), entre a Austria católica e a Prússia luterana; o de Varsóvia (1773); o de Frederiksham (1790), em que a Rússia se apossou da península da Finlândia.
} 
da nacionalidade e a proteção das comunidades designadas como minorias religiosas. O Congresso de Berlim de 1878, por exemplo, impôs à Rússia que se preocupasse com as diversas minorias religiosas do Império Otomano, pois a elas não poderiam ser atribuídos motivos de exclusão ou incapacidade no que se refere aos direitos civis e políticos de funcionar no serviço público, exercer diferentes profissões e indústrias, testemunhar nos tribunais etc. Essa concessão se estendeu não só a cristãos e ortodoxos, mas também a muçulmanos da Bulgária e Montenegro, judeus da Sérvia e da Romênia entre outros.

OCongresso de Berlim marcou uma transição, na opinião dos autores, ${ }^{2}$ do problema minoritário quanto ao Direito Internacional: as minorias religiosas tornaram-se minorias nacionais. A ideologia do Estado Nacional implicou universalizar a questão, sobretudo com o advento da Revolução Francesa e da proteção internacional das minorias nacionais, generalizada com o Tratado de Versalhes, “... que tentará a experiência global e coerente de um Direito Internacional das Minorias".

Esse princípio de remodelagem territorial sob a égide das nacionalidades levou à Guerra dos Balkans (1912-1913) e a de 1914-1918, sendo que os vencedores se organizaram para a formação da Sociedade das Nações (UN) em 1919-20, destinada à proteção das minorias dentro dos Estados em que viviam. ${ }^{3}$

Seguem-se várias reuniões para discussão de situações concretas de minorias dentro de seus territórios, como as de expatriados e refugiados, para melhor definir o tema e seus problemas, como exemplificam as Conferências de Helsinque, em 1975, quando a Iugoslávia toma a iniciativa de trazer a questão à CSCE, uma vez que tinha sido implodida pela União Soviética; a de Helsinque, de julho de 1992; a de Copenhague e a de Estocol-

2 Seção II - Les temps de nationalités, do livro de Rouland, N., et al. 1996, Droit des minorités et des peuples autochtones. p.167-174.

${ }^{3}$ Resumem-se, nos próximos dois parágrafos, ideias desenvolvidas em parte da seção III - La Société des Nations et la protection internationale des minorités, do livro citado na nota 2 , p.175-181. mo, ainda em 1992; a de Viena, de 1993; e tantas outras, posto que essas últimas foram posteriores à queda do muro de Berlim e à derrocada da União Soviética como Estado único, que englobava várias "minorias" nacionais.

Além disso, discute-se a situação dos direitos das minorias autóctones, tanto as das colônias européias como as asiáticas, as quais, mesmo com sua independência, enfrentam o fato de continuarem a ser tratadas como minorias, sem uma série de direitos e garantias. Incluem-se também os indígenas da América do Norte, que têm uma situação bem melhor do que a dos habitantes do Brasil. São inúmeras as Conferências da Organização das Nações Unidas (ONU), da Organização Internacional do Trabalho (OIT), que se iniciaram discutindo o direito à descolonização, e desde a Assembléia Geral da ONU de dezembro de 1960 e da resolução 1.514, com a Declaração sobre a outorga da independência dos países e dos povos coloniais, afirma-se que o objetivo fundamental da descolonização é a independência desses povos (1996, p.201).

\section{A questão do conceito}

Essa nova minoria, como categoria jurídicaque não é um conceito estatístico, mas sociológicodeveria incluir populações de todos os tamanhos, desde que tivessem características culturais específicas que as diferenciassem das outras. Contudo, a questão numérica hoje faz parte do conceito utilizado pela ONU, o que sociologicamente é incongruente, uma vez que o apartheid na África do Sul constitui exemplo máximo de discriminação de uma minoria negra e autóctone desse território, numérica e populacionalmente muito maior do que o inexpressivo número de brancos do mesmo país.

Francesco Capotorti, membro de uma subcomissão da ONU, conceitua minoria como

... um grupo numericamente inferior em relação ao restante da população de um Estado, em posição não dominante, onde os membros - nativos do Estado - possuem, do ponto de vista étnico, religioso ou linguístico, características que dife- 
rem das do resto da população e manifestam um sentimento de solidariedade, mesmo que de maneira implícita, com o efeito de preservar suas culturas, suas tradições, sua religião ou sua língua. (1996, p.218-219).

Os autores que escrevem sobre o tema mostram ser muito difícil uma definição unívoca sobre minorias, uma vez que se trata de questão complexa, delicada, que envolve o fato de lidar com diferenças de variadas dimensões entre os grupos étnicos, e que uma solução uniforme é quase impossível, pois se reveste de aspectos muito particulares em cada Estado nos quais se coloca a questão.

Diz ainda Capotorti que a luta contra as medidas discriminatórias e para a proteção das minorias, prende-se

... sobretudo ao fato de que as diferenças entre os grupos étnicos são na maioria das vezes profundamente enraizadas e a manifestação dum espírito de tolerância e aplicação rigorosa dos princípios da igualdade e não-discriminação são condições indispensáveis para manter a unidade política e espiritual dos Estados interessados em criar um clima de compreensão e de relações harmônicas entre os diferentes componentes da sociedade, em um país caracterizado pela diversidade de etnias, de religiões e de línguas (p.213).

A Recomendação 1.201, adotada em 1993 pela Assembleia parlamentar do Conselho Europeu, em seu artigo primeiro, dispõe:

... a expressão minoria nacional designa um grupo de pessoas em um Estado que: a) residem sobre um território deste Estado e são cidadãos; b) têm ligações antigas, sólidas e duráveis com esse Estado; c) apresentam características étnicas, culturais, religiosas ou linguísticas específicas; d) são suficientemente numerosos, porém menos que o resto da população desse Estado ou de uma região desse Estado; e) são animados pela vontade de preservar em conjunto o que faz sua identidade comum, notadamente sua cultura, suas tradições, sua religião ou sua língua (1996, p.235).

Durante esse período de discussão sobre as minorias na pauta internacional, com pontos de contato entre as preocupações apresentadas nas diversas reuniões, foram se constituindo o que se conhece hoje como Direitos Humanos. Trata-se de um marco histórico no campo político, que, segundo Paulo Lopo Saraiva (1983, p.9 e seq.), poderia ser pensado como o início do "Estado Libe- ral, ou Estado Constitucional, com as colônias americanas que encontraram sua expressão máxima no processo da Revolução Francesa promulgadora da Declaração dos Direitos do Homem e do Cidadão”, valorizando a democracia parlamentar, o respeito à lei e, especialmente, a promoção da dignidade da pessoa humana, característica primeira dos Direitos Humanos.

Ainda segundo esse autor, "as declarações de Direito, como matéria constitucional, compõem a moldura do Estado Liberal, contendo todas as diretrizes jurídicas, políticas, sociais, econômicas, desse período histórico". No entanto, o liberalismo excessivo, defendido por uma determinada facção social, e as necessidades econômicas e sociais da maioria das populações exigiam um novo tipo de Estado, com uma maior presença e representatividade política, social e jurídica. Adveio, então, o Estado Social de Direito, no qual é considerada essencial a participação do povo no processo político. As conquistas dos direitos e garantias individuais são ampliadas, protegendo não só os direitos individuais como também os direitos coletivos, mas intervindo também normativa e operacionalmente a fim de tutelar concretamente as prerrogativas individuais, construindo-se, assim, uma interação entre o Estado Social e o Estado de Direito.

O fim da Guerra Fria foi, conforme Lindgren Alves (1994), um fator determinante para a afirmação dos Direitos Humanos como tema global. Quando se violam as normas de Direitos Humanos, ferese a soberania popular, garantida praticamente em todas as constituições contemporâneas. As declarações, em contraposição aos tratados, convenções, pactos e acordos, não têm força jurídica compulsória, e "a ONU não tem poder físico para determinar as ações internas dos Estados, mas tem a capacidade de "embaraçar" os Governos, através de condenações morais constrangedoras." ${ }^{4}$ (p.44).

Norberto Bobbio (1992, p.25), ao se manifestar sobre o tema, diz: 4 O Autor utiliza essa explicação, citando Helga Ole
Bergensen em The power to embarrass, trabalho apre-
sentado ao Congresso Mundial de Ciência Política, Rio
de Janeiro, agosto, 1982 . 
o mais grave de nosso tempo, com relação aos direitos do homem, não é mais fundamentá-los, e sim protegê-los... Com efeito, o problema que temos diante de nós não é filosófico, mas jurídico, e num sentido mais amplo, político. Não se trata de saber quais e quantos são esses direitos, qual a sua natureza e fundamento, se são direitos naturais ou históricos, absolutos ou relativos, mas sim qual é o modo mais seguro para garanti-los, para impedir que, apesar das solenes declarações, eles sejam constantemente violados (p.55)

\section{OS DIREITOS HUMANOS E AS CONSTITUI- ÇÕES BRASILEIRAS}

Há também algumas discordâncias relativas ao direito de autodeterminação. A Iugoslávia, particularmente, tem discutido muito essas questões, oportunidade em que os conceitos de povo e de direito dos povos têm promovido bastante polêmica. Na interpretação de Luciano Mariz Maia (1993, p.251-293), a Constituição brasileira de 1988, ao reconhecer e respeitar uma série de direitos fundamentais dos índios, não empregou a palavra "povos", porque os incisos III e IX do art. $4^{\circ}$ de nossa Constituição referem-se ao direito político que os povos têm à autodeterminação e ao estabelecimento de um governo próprio e soberano, idéia não acolhida pela nossa Carta.

Segundo Paulo Lopo Saraiva, ${ }^{5}$ "As garantias individuais protegem o indivíduo face ao arbítrio e à ilegalidade estatal" (1983, p.27), e as garantias sociais protegem as classes menos privilegiadas economicamente em relação às economicamente mais fortes. Assim, as Constituições brasileiras, em vários artigos, usam a locução "direitos sociais”, segundo o autor, desde a de 1891, 1934, 1937, 1946 até a de 1967, defendendo o direito ao trabalho e à moradia. A Constituição de 1988, dita Constituição cidadã, retomou o direito à escola, acrescentou a referência à saúde e dedica um capítulo todo à ordem econômica e social.

Como afirma Paulo Saboya (1981, p.20 e seq.), com referência aos direitos dos índios, anteriormente existia no Brasil uma tutela orfanológica, e os índios não geriam seu destino de forma algu-

\footnotetext{
${ }^{5}$ Seguem-se informações colhidas às páginas 31-39.
}

ma. Desde as primeiras constituições republicanas, está expresso que são brasileiros: "1. os nascidos no Brasil, ainda que de pais estrangeiros, não residindo estes a serviço de seu país", sendo acrescido, em um dado momento, que estes são brasileiros natos: “... consequentemente o são, os índios”, mas são brasileiros “de segunda categoria legal, pois existem discriminações legais contra eles: desde o Código Civil são incapazes relativamente - junto com menores, oligofrênicos etc.", uma vez que "a tutela com índios não cessa e ele não perde nunca seu estado de índio, o que caracteriza um preconceito legal."

Nesse sentido, pode-se concluir com Aurélio Wander Bastos:

No que se refere aos silvícolas, para usar a linguagem jurídica, a preocupação protetora tem uma vertente somente identificável com os menores... Todavia, no que se refere aos indígenas, o dispositivo não tem qualquer caráter de transitoriedade, como antigamente acontecia com a mulher casada, mas de estigma jurídico com evidentes efeitos no exercício da cidadania (1985, p.86).

O Capítulo VIII - Dos Índios - na Constituição do Brasil de 1988, em seu artigo 231, integrado por sete parágrafos, reconhece a organização social, a língua, os costumes, as tradições e crenças dos índios e seus direitos originários sobre as terras que ocupam, tendo a União de respeitar e proteger todos os seus bens, e, no art. 232, declara serem suas comunidades e organizações partes legítimas para ingressar em juízo em defesa de seus direitos e interesses. Essa postura constitucional possibilitou às nações indígenas defenderem-se em causa própria, o que não era possível sob a tutela da FUNAI.

Contudo, e apesar de toda a vasta argumentação e discussão sobre o tema do direito consuetudinário dos índios, do pensamento atual sobre a autonomia dos povos, dos direitos humanos, dos pactos e convenções internacionais dos quais somos signatários, o novo Código Civil brasileiro (Lei $n^{\circ} .10 .406$ de 2002) não se liberta do art. 6. ${ }^{\circ}$, parágrafo único, do anterior Código de 1916, e consagra, no parágrafo único de seu art. $4 .^{\circ}$, refe- 
rente às incapacidades relativas, que "a capacidade dos silvícolas será regulada por legislação especial", o que significa voltar, mais uma vez, à mentalidade paternalista-protecionista, que não vê o direito dos grupos indígenas e desrespeita, de um lado, os princípios da Constituição de 1988, exarados nos artigos 231 e 232, e, de outro, a dignidade da pessoa do índio e a autonomia dos povos indígenas no Brasil, retornando-os à categoria de relativamente incapazes.

Estudiosos evocam a problemática minoritária sob o ângulo dos direitos coletivos e não apenas subjetivos. Os indígenas brasileiros se enquadram nas várias definições de minorias propostas pelos organismos internacionais, e a eles deveriam ser aplicados os direitos coletivos e subjetivos concernentes a esse tipo de sociedade, conforme está afirmado nas várias resoluções internacionais, das quais somos signatários desde 1966.

Autores nacionais têm se debruçado sobre o tema das políticas indigenistas - e, neste artigo, recuperamos em parte o debate que se desenrolou durante a década de 1980 -, buscando uma definição mais adequada à questão indígena, tendo em vista a sua condição de índio e as leis do Estado brasileiro. Assim, há uma imensa e intensa discussão para resolver: primeiro, um problema também enfrentado em nível internacional, relacionado à distinção entre assimilação e integração, para o qual a contribuição de Pedro Agostinho (1980, 1981, 1982) é fundamental para o encaminhamento de uma discussão mais elaborada, a fim de se equacionarem os conceitos, pois pelo Código Civil de 1916, o índio, integrado na sociedade, deixa sua condição de indígena.

O outro aspecto que vem desafiando antropólogos, juristas e indigenistas no Brasil é a definição de índio, grupos tribais, nações indígenas, minorias étnicas etc., ${ }^{6}$ até porque a FUNAI, com a intenção de se ver livre de problemas, decidiu,

${ }^{6}$ Entre eles, podemos citar antropólogos e advogados: Darcy Ribeiro, Roberto Cardoso de Oliveira, Maria Manuela Carneiro da Cunha, David Maybury-Lewis, Pedro Agostinho, Eduardo Viveiros de Castro, Paulo Saboya, Dalmo DallarI, C. F. Marés de Souza Fo., José Maria Alencar, José Heder Benatti, e outros tantos. sem consultar especialistas, resolver a questão de forma casuística, evidentemente sob a pressão dos grupos econômicos. Nesse sentido, afirma Eduardo Viveiros de Castro (1981): " "O que a FUNAI argumenta é que ela possui poucos recursos, que é preciso racionalizar a política de proteção [...] Então precisa ter uma ideia de quem éíndio e quem não é". O autor acha bastante curioso ter de estabelecer um critério de "indianidade", porque tem indio demais...

Para Paulo Saboya, “... a única definição de que se tem no Brasil é a de índio. Pergunta: e os negros, os arianos, e outros nacionais? (1981, p.20). Pela Lei 6.001, conhecida como "Estatuto do Índio":

Índio ou silvícola é todo indivíduo de origem e ascendência pré-colombiana, que se identifica e é identificado como pertencente a um grupo étnico, cujas características culturais o distinguem da sociedade nacional.

Então, pensa ele:

Deve haver um erro aqui: se são distintos da sociedade nacional, e não na sociedade nacional, eles não são membros, não compõem a sociedade nacional. Colocado como está, a leitura seria de que eles não são da sociedade nacional... Qual a sua nacionalidade, se por definição são brasileiros natos? Porque recebe o índio tratamento legal diferente das outras nações?

Denis Werner (1985, p.47) também se manifesta:

Infelizmente, a jurisprudência exige que os antropólogos forneçam uma definição que sirva para qualquer fim. E, no caso dos índios, a ambiguidade sobre quem é índio pode trazer grandes injustiças.

Como exemplo, o autor cita Nacke, quanto ao "caso de um homem que foi expulso do Posto Indigena Xapecó, S.C., por ser 'branco', enquanto seu irmão ficou no posto por ser "mestiço".

${ }^{7}$ Ver Eduardo Viveiros de Castro In: O Índio e o Direito. PAINEL. Rio de Janeiro: OAB, 1981. p.63- 75. (Série Debate): para acessar o interessante debate sobre como surgiu essa ideia de definir critérios de "indianidade" pela FUNAI, o que foi uma forma de retaliação pelo fato de o cacique Juruna ter conseguido ir ao Tribunal Russell, por causa de Mandado de Segurança impetrado no Tribunal Superior de Recursos, (equivalente ao atual STF), mesmo quando seu Tutor, a Funai, não havia permitido. 
O DIREITO DOS ÍNDIOS OU O DIREITO PARA OS ÍNDIOS?

Roque de Barros Laraia (1985, p. 61-62) faz interessante paralelo entre a maneira de os Estados Unidos da América do Norte e o Brasil tratarem os habitantes primitivos e originais de seus países. Nos EUA, para dirimir dúvidas e conflitos entre os grupos indígenas e o Estado, em geral envolvendo questões de terras, esse último se utilizou "das negociações diplomáticas ou de guerra aberta”, mas se apercebeu de que era melhor negociar do que guerrear, e

... já no século passado, escolheu a alternativa chamada 'diplomacia vermelha' e, a partir dessa tradição de reconhecer a soberania das nações indígenas, malgrado as atitudes que muitas vezes a contradizem, encontra-se registrada, na Constituição Federal, em seu artigo 1. ․, Seção 8, quando determina que o Congresso terá poder [...] para regular o comércio com as nações estrangeiras, entre os vários Estados e com as tribos indígenas.

No caso brasileiro, ocorre o contrário, continua o autor:

Em nenhum momento foram reconhecidos os direitos dessas pequenas nações em existirem como tal. Até bula papal foi preciso para reconhecer os mesmos como seres humanos e, em lugar de negociações, ocorreram guerras encobertas que utilizavam os braços armados da própria sociedade civil. Quando declaradas, eram rotuladas eufemisticamente de 'guerras justas', sob o pretexto de extirpar a selvageria e o paganismo.

Como diz Ana Valéria Leitão (1993, p.229230), o direito de um povo, consuetudinário ou não, constitui elemento básico de sua identidade étnica: o direito interno aos povos indígenas de todo o mundo é integralmente constituído de acordo com seus usos e costumes, e ninguém deixa de reconhecer o sistema jurídico inglês, apesar de não existir uma constituição escrita. Assim, fica a pergunta: por que as leis de sistemas legais indígenas que não são escritos, mas que têm raízes em princípios tão respeitáveis quanto as leis não-indígenas, não têm o mesmo valor que as nossas?

Há grupos indígenas, por exemplo, cujas normas relativas à família e ao casamento não pro- íbem a poligínia, o que, aliás, também ocorre com povos asiáticos e africanos. Como lidar com essas diferenças quando aqui chegarem pessoas desses países, como foi o caso de afegãos, recentemente? Ou de qualquer outro grupo que pratique esse mesmo regime de casamento, como os seguidores da religião muçulmana, aqui nascidos ou residentes?

Tendo em vista o Direito Internacional, qual a atitude legal a ser tomada? No caso dos índios,

O Estatuto do Índio dizia que deveriam ser respeitados os usos, costumes e tradições nas relações de família, na ordem de sucessão [...] se optarem pela aplicação do direito ‘comum'(artigo 6º .) [do CC de 1916]. Mas não há resposta sobre quem aplica esta norma subsidiária, será o juiz federal da sessão correspondente, ou o simples pedido para que um juiz 'comum' julgue é o bastante para reconhecer a opção que afaste a norma subsidiária? (Souza Filho, 1999, p.160-161).

Com suas lições de bom senso, jurídicas e de civismo, transcrevemos de Norberto Bobbio (1992, p.210-211):

As boas razões de tolerância não nos devem fazer esquecer que também a intolerância pode ter suas boas razões. Todos nós já vimos, cotidianamente, explodirem exclamações do tipo 'é intolerável que...', 'como podemos tolerar que...?', 'tudo bem quanto à tolerância, mas ela tem limites' etc. Tolerância, em sentido positivo, se opõe a intolerância (religiosa, política, racial), ou seja, à indevida exclusão do diferente.

A tolerância implica algo difícil de ser aceito pelas partes em litígio e é um caminho de duas mãos. Mas se o Estado, o lado forte da questão, não oferece tolerância às minorias, como pedir a elas tolerância frente ao Estado? É evidente que a resistência dos grupos indígenas, bem como de outros grupos de "excluídos", vale-se de qualquer argumento ou instrumento, mesmo da força (aliás, uma conduta usual do Estado em relação às minorias), quase única forma de obter resultado, uma vez que os interesses econômicos e sociais dos mais fortes têm, em geral, melhor trânsito na Justiça, além do fato de que a demora e o pouco caso resultam, muitas vezes, na perda do fumis boni jure.

Um caso que, infelizmente, não é exemplar no que se refere ao pedido, mas o é quanto ao 
esforço e à consciência ecológica, é o do grupo indígena Guarani, de Mangueirinha, no Paraná, que conseguiu obter um abaixo-assinado com um milhão de assinaturas para salvar a última reserva mundial de Araucária, questão que estava sendo julgada por um dos Tribunais Superiores de Brasília. Como nos conta Marés de Souza Filho (1999, p.160),

As principais lideranças do povo Guarani, presentes em Brasília, por meio de um deputado, conseguiram marcar audiência com o Presidente do Tribunal para apresentar-lhe o abaixo-assinado. $\mathrm{O}$ dia marcado foi uma segunda-feira de manhã. Como no conto de Kafka, não passaram do primeiro porteiro [...] porque lhes faltava, a cada um, uma gravata.

\section{Continua o autor em nota de rodapé}

Este fato ocorreu em 1982. O abaixo-assinado foi entregue pelo deputado que conseguira a audiência, um tempo depois. Quando do julgamento, foi anulada a sentença que considerava a reserva propriedade privada, por cerceamento de defesa. Em janeiro de 1998 ainda não havia nova sentença.

A perda do fumis boni jure, nesse caso, implica uma perda para toda a população brasileira, para não mencionar o mundo como um todo.

No Estatuto do Índio, entre outras exigências legais, encontramos, nos artigos 12 e 13, aquela dos registros civil de óbito e nascimento, que deverão ser feitos de acordo com a legislação comum, a pedido do interessado, por autoridade competente etc. Desnecessário detalhar outros artigos para se perceber a impossibilidade de sua efetivação até para populações ribeirinhas de estados do norte e centro-oeste brasileiro, quanto mais para comunidades indígenas.

Para David Maybury-Lewis (1992, p.12),

As leis teoricamente garantem aos índios proteção e participação num estado multiétnico. Na prática, o governo adota o pressuposto de que os índios devem abandonar seus modos de vida a fim de participarem da cultura monolítica do Brasil [... o que] perpetua uma trágica incompreensão, que conturbou a história das Américas, de que a simples existência de culturas indígenas é uma ameaça ao sistema de valores e à integridade de estados nacionais.
E a cultura brasileira não é tão monolítica assim, verificando-se bolsões diferenciados que refletem os constantes conflitos entre os grupos, dos quais os índios, os sem-terra, os sem-teto e outros grupos minoritários são evidências.

Muitas das vezes, as leis são boas, e, assim como a má, a boa jurisprudência existe. Todavia, o índio

... sofre uma verdadeira indigência de recursos para a prestação jurisdicional no que diz respeito à distância, à reunião de provas, à carência de recursos sociais e econômicos, além de problema processual [...] a se resolver se o índio sozinho pode ou não demandar em juízo, porque muitas vezes ele é constrangido a acionar o próprio órgão de tutela, e não existe ainda jurisprudência a esse respeito [...] se não existe uma jurisprudência já firmada, muito menos vai existir uma jurisprudência firmada em favor do índio [... daí] a conveniência de buscarmos recursos jurídicos, como uma forma possível de evitar ou de remediar violências cometidas contra índios ou comunidades tribais.

\section{Busca-se}

... primeiro dar aos índios um conhecimento crítico da legislação aplicável ou em vigor, e, em segundo lugar, apresentar um critério à via judicial [...] construir uma jurisprudência pró-índio, que não existe no país [...] e sensibilizar os membros do Poder Judiciário, do Ministério Público e os advogados [...] para que possam aplicá-la ou invocá-la (Gaiger, 1981, p.94-96).

José Reynaldo de Lima Lopes (1994, p. 8687), ao se referir aos habitantes urbanos dos cortiços, para os quais as leis do inquilinato, por uma série de circunstâncias por ele descritas, não tem eficácia em juízo, escreve:

No direito existem campos enormes de relações que vão escapando à possibilidade de controle pela via jurídica institucional [...] e que se fosse a nossa cultura jurídica sensível para a oralidade dos contratos, todos os moradores de corticos teriam mais chance. Mas a idolatria do escrito, no processo e no direito civil, impede o reconhecimento de situações graves da vida cotidiana.

Ele pergunta: "Existe, de fato, a possibilidade de acesso à Justiça para parcelas cada vez crescentes da população brasileira?” E continua, com uma crítica sobre a afirmação, questionável, de que

... o Judiciário não precisa de reforma, mas de
meios para continuar fazendo o que sempre fez, 
na medida em que [o que se] se questiona não é a sua eficácia no mundo ideal das relações entre as normas, mas no mundo real das contradições sociais.

Paulo Saboya (1981, p.25), ao ser perguntado por que não se consegue demarcar as terras indígenas (o que deveria ter acontecido conforme o Estatuto do Índio de 1973, até cinco anos após a promulgação), diz que o choque se inicia porque se trata de uma propriedade comunal e não condominial, o que se traduz em uma dificuldade básica, ou seja, "a sociedade não consegue engolir a pílula da propriedade comunal dentro do sistema capitalista".

Nesse sentido, continua Maybury-Lewis (1992, p.11):

Primeiramente, os próprios índios devem ser consultados e seus pontos de vista devem ser compreendidos e considerados. Em segundo lugar, o futuro econômico dos índios deve ser considerado como uma parte integrante do projeto. [...] aspecto frequentemente ignorado porque julgam serem os índios 'obstáculos ao desenvolvimento' e, portanto, [...] as sociedades indígenas devem ser removidas, afastadas [...] confinadas em reservas deploráveis.

Hoje, observa-se que muitos grupos têm condições de se manter, de contribuir para a economia e para sociedade mais ampla, sem abandonar sua própria cultura. E aqueles menos favorecidos pelo ambiente físico, por meio de projetos educacionais e ambientais, como os que citamos a seguir, também podem contribuir sem ter de abdicar de seu modo de vida.

\section{ADEMOCRACIA PLURALEAS PERSPECTIVAS DE DIREITOS PARA A MINORIA INDÍGENA}

O Estado Liberal e sua etapa seguinte, o Estado Social, caracterizaram-se por uma centralização de poder que faz parte do projeto autoritário de Governo e de Estado, e é ineficiente como controle, particularmente nos países de terceiro mundo, com grandes territórios e populações. As grandes modificações ocorridas na sociedade mundial, especialmente na década de 1980, vêm desa- guando no Estado Social de Direito, também dito Democracia Dialógica, que caminha na direção de uma descentralização democrática, a qual tende a privilegiar o diálogo entre os grupos existentes na sociedade, fortalecendo o poder local em detrimento do central.

Ao que parece, esse objetivo deveria ser mais fácil de ser concretizado em países economicamente mais ricos, com territórios e populações pequenas (face aos do terceiro mundo), como os da Europa, mas os conflitos minoritários quanto a língua, história, religião, interesses políticos, econômicos, que pululam em todos os seus rincões, fazem-nos duvidar da afirmação. No mundo economicamente subdesenvolvido, leia-se mais pobre, onde os territórios e populações são bem maiores e mais espalhados, devido a diversidades físicas, econômicas e culturais de seus habitantes e a diversidades ambientais, fica bem mais distante a possibilidade de se implementar essa proposta.

Essas mudanças de valores exigem uma sociedade civil organizada, em que a "educação coletiva" para a resolução de problemas e conflitos sociais deveria se fundamentar numa postura conciliatória, dependente da comunicação, informação e divulgação, bem como da ação de cada um e dos vários setores da sociedade. As idéias de como construir uma sociedade dialógica tem de ser compartilhada pelos seus integrantes e, nesse contexto, o poder local assume as rédeas do processo. O Estado Social permitiu uma abertura para o debate na sociedade, encaminhando-se para o que é chamado de Estado Social de Direito ou Estado Democrático de Direito.

Certas mudanças ocorridas nas nações indígenas - por pressão de indigenistas, antropólogos, juristas, missões religiosas, ONGs, pela preocupação do governo com sua imagem nas repercussões internacionais e por força de tratados de direitos de minorias e direitos humanos - conseguiram, se não estancar, pelo menos refrear alguns abusos junto aos poderes constituídos, principalmente quanto a invasões de suas terras. Nessa faina, foi se tornando possível a preparação e a educação formal de alguns índios, que se organizaram para defender 
seus povos junto aos poderes constituídos, numa postura que privilegia o direito constitucional.

Os grupos indígenas vêm trilhando um caminho em direção a uma democracia partilhada, dialógica, a duras penas. Assim, estruturou-se o Conselho Indigenista Missionário (CIMI), órgão da Conferência Nacional dos Bispos do Brasil (CNBB), cuja finalidade era dar assessoria aos missionários que atuavam nas comunidades indígenas, e que tentou, sem sucesso, chegar a um consenso de interesses com a FUNAI. ${ }^{8}$

Em 1974, o CIMI promoveu o Primeiro Encontro de Chefes Indígenas, para que líderes e representantes dos vários grupos pudessem se conhecer e discutir seus problemas comuns. Por alguma razão, a nova diretoria da FUNAI, em 1977, proibiu os missionários do CIMI de adentrarem em áreas indígenas, mas outros grupos de apoio à causa começaram a surgir, e se converteram em canais eficazes de denúncia e pressão, utilizandose de fóruns e publicações de âmbito nacional.

Formaram-se, assim, a Associação Nacional de Apoio ao Índio (ANAI), com sede em Porto Alegre e subsedes em outros estados e a Comissão Pró-Índio de São Paulo (CPI-SP), que apoia a União das Nações Indígenas (UNI), fundada em 1980, que promovem encontros e assembleias de lideranças indígenas e cujo departamento jurídico se empenha em elaborar uma legislação indigenista com a participação dessas lideranças, além de prestar assessoria aos grupos. Também em São Paulo funciona o Centro de Trabalho Indigenista (CTI), que desenvolve projetos para áreas específicas, e o Instituto Sócio Ambiental (ISA), que substituiu o Núcleo de Direito Indígena (NDI), ampliando-o para outras finalidades. Em Cuiabá, focalizando a questão indígena e dos camponeses, localiza-se o Centro de Documentação Terra e Índio (CDTI).

De 1974 a 1980, foram levadas a cabo 13 assembleias de chefes indígenas de várias áreas do país, que lograram publicar um boletim em âmbito nacional, e o jornal Porantin, que alerta sobre as

\footnotetext{
${ }^{8}$ Este e os cinco parágrafos seguintes resumem as páginas 266-269 do artigo de Carmen Sylvia de Alvarenga Junqueira e Eunice Paiva, 1988. p.243-269.
}

repetidas violações dos direitos indígenas. Em 1980, estrutura-se a Sociedade Brasileira de Indigenistas, que se propunha a dialogar com a FUNAI, uma vez que seus funcionários ficavam em Brasília, na maior parte do tempo planejando e implementando decisões contrárias às comunidades dos índios, não se preocupando em conhecer determinados indivíduos de tribos, que, cooptados, agiam contrariamente aos interesses maiores do seu grupo.

A FUNAI não reconheceu a Sociedade e nem a União das Nações Indígenas (UNI), declarando-se a única e legítima representante dos índios. Essa declaração se baseava em determinação do Presidente da República, fundamentada no relatório do SNI, que dizia não ser prudente que as diferentes nações indígenas se agrupassem em um só organismo.

Em 1981, reuniram-se em São Paulo 73 líderes e 32 entidades de apoio, com o fim de preparar o Primeiro Encontro Nacional de Povos Indígenas, realizado em junho de 1982, com a presença de 228 líderes que representavam 48 nações. No Segundo Encontro, organizado por Mario Juruna e pela UNI, em abril de 1984, compareceram 450 líderes tribais de mais de 50 povos indígenas. Nessas reuniões, as propostas e reivindicações se concentraram nos direitos de ir e vir, de liberdade de reunião, de se organizarem e de não serem declarados "não-índios" à sua revelia, de demarcação de suas terras e da emissão e entrega de seus títulos de propriedade.

Vale a pena ressaltar, nesse momento, o papel do chefe da aldeia Xavante, Mário Juruna. De acordo com Junqueira e Paiva (1988)

Em 1980 foi o chefe da aldeia Xavante Namunkurá, Mario Juruna, que havia se convertido no representante mais importante da luta indígena no Brasil, eleito presidente de Comissão do $4^{\circ}$. Tribunal Bertrand Russel de Direitos Humanos.

Segundo Carlos Marés de Souza Filho (1993), Juruna, recebeu

convite para viajar para o exterior para apresentar a situação do indígena brasileiro a entidades de defesa dos direitos humanos. Valendo-se da tutela imposta pelo Estatuto do İndio, o Ministro 
do Interior, chefe hierárquico do Presidente da FUNAI, proibiu sua saída do país.

Conforme nos conta Rafael José de Menezes Bastos (1982, p.59-60), que teve em mãos os autos desse processo,

\begin{abstract}
Posta a disputa ao nível judiciário, o caso Mário Juruna se conforma basicamente pela impetracão, no Tribunal Federal de Recursos, dos Habeas Corpus sob n ${ }^{\circ} 4.876$ (de 13 de novembro de 1980) e 4.880 (do seguinte dia 17), em favor da liberdade do Chefe Xavante de ir e vir, podendo, assim, comparecer ao IV Tribunal Bertrand Russel. Note-se que a FUNAI e o Ministério do Interior publicamente - através de jornais, revistas etc.- não concederam autorização ao Sr. Juruna para isto poder concretizar, o que se evidenciou, praticamente, pela também negativa da Polícia Federal de a ele conceder passaporte.
\end{abstract}

Conclui esse autor que a causa foi ganha por Juruna “.... exatamente em função da inspiração que os ministros do Tribunal Federal de Recursos foram buscar na Declaração Universal dos Direitos do Homem”.

Citando Eduardo Viveiros de Castro (1982, p.11), foi por meio de recurso que "O TRF considerou que a condição de tutelado de Juruna não legitimava a proibição de viajar [...] um caso límpido de abuso do poder”. Mesmo assim, “... o habeas corpus obteve 15 votos a favor e nove contra, com o que pode sair para a Holanda onde assistiu a parte final dos trabalhos do $4^{\circ}$. Tribunal." (Junqueira; Paiva, 1988, p.267),

Em 1981, Juruna foi eleito deputado federal pelo Rio de Janeiro com 31.805 votos e teve seu Projeto de Lei, ${ }^{\circ} 661-A$, que previa uma reestruturação da FUNAI com a participação dos índios, aprovado em plenária do Congresso, o que evidenciou uma "nova consciência étnico-política voltada contra a dominação colonial de que o índio foi objeto", conforme se expressa João Pacheco de Oliveira (1985, p.26).

Com a abertura propiciada pelo art. 232 da Constituição Federal de 1988, as associações indígenas registradas na forma de sociedades civis, na Amazônia, passaram, em uma década, de 10 para 180, compreendendo os seis estados da Amazônia (AM, RO, RR, AC, PA, AP), e são estimadas atualmente em mais de 250 se considerarmos o território compreendido pela chamada Amazônia Legal. Algumas dessas organizações têm recursos externos, em geral orientados para projetos de saúde, educação, autossustentação, gestão territorial etc., com colaboração de ONGs ambientais e sociais, preocupadas também com os efeitos possíveis da globalização nas questões do meio ambiente. Entretanto, em âmbito nacional, o fator mais importante foi a

\begin{abstract}
Constituição Federal de 1988 que possibilitou às associações se constituírem em pessoas jurídicas...[e envidou] o processo de retração do Estado da gestão direta da "questão indígena" e o esvaziamento político orçamentário da FUNAI, criada há três décadas pelo regime militar no quadro de suas políticas de desenvolvimento da Amazônia. ${ }^{9}$
\end{abstract}

Não foi apenas o número de sociedades de direito civil que cresceu - e aqui nos referimos apenas àquelas da Amazônia -, mas também o número de índios, que era, antes do censo de 2000 , estimado em cerca de 326 mil pessoas, de 206 etnias. Considerando-se 554 territórios indígenas em 24 estados (Rodrigues, 2000, p.6), essa população aumentou para mais de 700 mil, segundo o IBGE, de acordo com dados do censo demográfico de 2000.

Em 1999, foi instalada no país uma nova política de saúde para os povos indígenas, sob a responsabilidade da Fundação Nacional de Saúde (FUNASA), criando-se 34 Distritos Sanitários Especiais Indígenas (DISEI), formados segundo critérios étnicos e geográficos. No Parque Indígena do Xingu, por exemplo, vivem 17 tribos que tiveram como formadores e lutadores para sua preservação física e cultural, além da preservação da fauna e da flora, os irmãos Villas Boas, com o apoio de intelectuais e políticos preocupados com os índios, o que constitui um exemplo de convivência dessas populações e do seu crescimento demográfico. Aí existe um DISEI que deu continuidade ao trabalho desenvolvido na área desde 1965 pela Escola Paulista de Medicina (EPM), hoje integrante da Universidade Federal de São Paulo

${ }^{9}$ Esses dados e as informações a seguir provêm do artigo de Bruce Albert, 2001, p.197-207. 
(UNIFESP). O interessante é que, nesse Distrito Sanitário, vivem sempre médicos da UNIFESP, e índios de todos os grupos têm uma participação representativa e ativa no Conselho de Saúde e no de Lideranças, recebendo formação e capacitação como Agentes Indígenas de Saúde, escolhidos pelas próprias comunidades (Pagliaro, 2002).

Os fatos e as situações mencionadas, quebrando uma tradição de leis que vêm, desde 1500, mais desprotegendo do que protegendo os povos indígenas, provavelmente só puderam acontecer por estarmos em uma nova era relativa aos direitos, da qual faz parte a ideologia presente no Estado de Direito, que, em tese, privilegia questões como o diálogo e o multipluralismo.

No que tange à organização das comunidades indígenas, Lúcia Valle Figueiredo, ao discorrer sobre "pessoa de direito público e de direito privado", em artigo publicado na Enciclopédia Saraiva de Direito, diz que

em determinados casos, como, à guisa de exemplo, das empresas estatais, estamos, nitidamente, diante de um terceiro regime jurídico, ainda não rotulado pelo direito e em que se imbricam peculiaridades do regime de direito privado e de direito público (apud Gonçalves, 1993, p.250).

\section{Continua o procurador da República:}

Devem denominar-se, no Estatuto do Índio, pessoa jurídica de direitos indígenas, o que lhes garantirá, na prática, o reconhecimento de sua organização social (art.231, da Constituição), além de dar espaço para que se possa admitir a existência de novo ente, que se insere, pela Constituição de 1988, no ordenamento jurídico brasileiro (Gonçalves, 1993, p.250). ${ }^{10}$

A educação e o preparo de toda a sociedade a fim de tornar possível a democracia dialógica são cada vez mais importantes. Expandem-se, assim, as possibilidades do diálogo e do reordenamento das relações com os povos indígenas, para, entre outras coisas, não perdermos o barco de constituir uma sociedade com comunidades integradas, par-

${ }^{10}$ Também Carlos Marés de Souza Filho, faz sugestão semelhante em seu capítulo, Tutela aos índios: proteção ou opressão? In: Santilli, Juliana (Coord.) Os direitos indígenas e a constituição. Porto Alegre: Sergio Fabris / NDI, 1993. p.296-312. ticipando no desenvolvimento social e econômico do país. Se não agirmos rapidamente, as mudanças que estão aí nos atropelarão.

(Recebido para publicação em julho de 2009) (Aceito em setembro de 2009)

\section{REFERÊNCIAS}

AGOSTINHO, Pedro. Emancipação do índio. Ciência e Cultura, São Paulo, v.32, n.2, p.173-183, fev., 1980.

.In: O Índio e o Direito. PAINEL.Rio de Janeiro: OAB, 1981. p.26-62. (Série OAB/RJ Debate)

Incapacidade civil relativa e tutela do índio. In: SANTOS, Silvio Coelho dos et al (Org.) O índio perante o Direito: ensaios. Florianópolis: Ed. UFSC, 1982. p.61-88.

ALBERT, Bruce. Associações Indígenas e Desenvolvimento Sustentável na Amazônia Brasileira. In: POVOS indígenas no Brasil 1996/2000. [S.1.]: Instituto Sócio Ambiental, 2001. p.197-207.

ALVES, José Augusto Lindgren. Os direitos humanos como tema global. São Paulo: Perspectiva, 1994.

BASTOS, Aurélio Wander. As terras indígenas no Direito Constitucional brasileiro e na jurisprudência. In: SANTOS, Silvio Coelho dos et al (Org.) Sociedades indígenas e o Direito: uma questão de direitos humanos. Florianópolis: UFSC/CNPq,1985. p.85-98.

BASTOS, Rafael José de Menezes. Sobre a noção de tutela dos povos e indivíduos indígenas pela Uniấo. In: SANTOS, Silvio Coelho dos et al (Org.) $O$ índio perante o Direito: ensaios. Florianópolis: Ed. UFSC, 1982.

BATISTA, Nilo. In: O Índio e o Direito. PAINEL, Rio de Janeiro: OAB, 1981. p.97-98. (Série OAB/RJ Debate)

BOBBIO, Norberto. A era dos direitos. Rio de Janeiro: Campus, 1992.

CASTRO, Eduardo Viveiros de. Índios, leis e políticas. In: SANTOS, Silvio Coelho dos et al (Org.) $O$ índio perante $o$ Direito: ensaios. Florianópolis: Ed. UFSC, 1982.

GAIGER, Júlio. In: O Índio e o Direito. PAINEL. Rio de Janeiro: OAB, 1981. p.93-96. (Série OAB/RJ Debate)

GONÇALVES, Wagner. Natureza Jurídica das comunidades indígenas. Direito público e Direito Privado. Novo Estatuto do Índio. Implicações, In: SANTILLI, Juliana

(Coord.) Os direitos indígenas e a constituição. Porto Alegre: Sérgio Fabris, 1993. p.241-250.

JUNQUEIRA, Carmen Sylvia de Alvarenga; PAIVA, Eunice. La legislación brasileña y las poblaciones indígenas en Brasil. In: STAVENHAGEN, Rodolfo. Derecho indígena y derechos humanos en América Latina. México: Instituto Interamericano de Derechos Humanos/El Colégio de México, 1988.

LARAIA, Roque de Barros. O índio e o Estado. In: SANTOS, Silvio Coelho dos et al (Org.) Sociedades índígenas e o Direito: uma questão de direitos humanos - Ensaios. Florianópolis: UFSC/CNPq, 1985.

LEITÃO, Ana Valéria Nascimento Araújo. Direitos culturais dos povos indígenas: aspectos do seu reconhecimento. In: SANTILLI, Juliana (Coord.) Os direitos indígenas e a constituição. Porto Alegre: Sérgio Fabris, 1993. p.225-240. 
LOPES, José Reynaldo de Lima. A crise da norma jurídica e a reforma do Judiciário. In: FARIA, José Eduardo (Org.) Direitos Humanos, Direitos Sociais e Justiça. São Paulo: Malheiros, 1994. p.68-93.

MARIZ MAIA, Luciano. Comunidades e organizações indígenas. Natureza jurídica, legitimidade processual e outros aspectos. In: SANTILLI, Juliana (Coord.) Os direitos indígenas e a constituição. Porto Alegre: Sergio Fabris NDI, 1993. p.251-293.

MAYBURY-LEWIS, David. Prefácio. In: SANTOS, Silvio Coelho dos (Org.) O índio perante o Direito: ensaios. Florianópolis: Ed. da UFSC, 1982.

OLIVEIRA, João Pacheco de. Contexto e horizonte ideológico; reflexões sobre o Estatuto do Indio. In: SANTOS, Silvio Coelho dos et al (Org.) Sociedades indígenas e o Direito: uma questão de direitos humanos - ensaios. Florianópolis: Ed. UFSC/CNPq, 1985. 17-30.

PAGLIARO, Heloisa. A revolução demográfica dos povos indígenas do Brasil: a experiência dos Kaiabi do Parque Indígena do Xingu - Mato Grosso- 1970-1999. 2002. Tese (Doutorado em Saúde Pública) Faculdade de Saúde Pública/USP. São Paulo, 2002.
RODRIGUES, Douglas. Relatório Técnico - Distrito Sanitário Especial Indígena do Xingu, jun., 2000.

ROULAND, Norbert; PIERRÉ-CAPS, Stephane POUMAREDE, Jacques. Droit des minorités et des peuples autochtones. Paris: Presses Universitaires de France, 1996.

SABOYA, Paulo. In: O Índio e o Direito. PAINEL. Rio de Janeiro: OAB,1981, p.20-25. (Série OAB/RJ Debate)

SARAIVA, Paulo Lopo. Garantias constitucionais dos Direitos Sociais no Brasil. Rio de Janeiro: Forense, 1983.

SOUSA FILHO, Carlos Frederico Marés de. Tutela aos índios: proteção ou opressão?. In: SANTILLI, Juliana (Coord.) Os direitos indígenas e a constituição. Porto Alegre: Sergio Fabris /NDI, 1993. p.296-312.

O renascer dos povos indígenas para o Direito. Curitiba: Juruá, 1999.

WERNER, Denis. Duas respostas simplistas sobre o direito dos índios à terra. In: SANTOS, Silvio Coelho dos et al (Org.) Sociedades indígenas e o Direito: uma questão de direitos humanos - ensaios. Florianópolis: UFSC/CNPq 1985. 


\section{THE MINORITIES RIGHTS AND THE INDIGENOUS NATIONS IN BRAZIL}

\section{Maria Stella Ferreira Levy}

The present paper regards issues on history, law, economy, anthropology, sociology, politics, concerning minorities, pointing out some significant cornerstones of the Brazilian indigenist policies in the decade of 1980 . With respect to the human rights applied to minorities, if previously their fulcrum was the protection of those rights, today their regulation and juridical warranty are demanded, fomenting a realignment of these relationships. That was a great contribution of the Constitution of 1988 in what regards the indigenous communities that inhabit Brazilian national territory.

KEYWORDS: minorities, indigenous peoples, constitutional rights, human rights, laws.

\section{LE DROIT DES MINORITES ET LES NATIONS INDIGENES AU BRESIL}

\section{Maria Stella Ferreira Levy}

Cet article traite de sujets de l'histoire, du droit, de l'économie, de l'anthropologie, de la sociologie, de la politique liés à la question des minorités, en mettant en évidence quelques étapes importantes de la politique indigène brésilienne des années 1980. En ce qui concerne les droits de l'homme appliqués aux minorités, si avant, les fondements en était la protection de ces droits, aujourd'hui on exige leur régularisation et qu'ils jouissent d'une garantie juridique grâce à une réorganisation de ces relations. Telle a été la grande contribution apportée par la Constitution de 1988 pour les communautés indigènes qui habitent sur le territoire national.

Mots-CLÉS: minorités, peuples indigènes, droits constitutionnels, droits de l'homme, lois.

Maria Stella Ferreira Levy - Doutora em Saúde Pública e em Direito Civil. Professora Associada do departamento de epidemiologia da Faculdade de Saúde Pública da Universidade de São Paulo - USP. Livre Docência em Epidemiologia (FSP/USP, 1989) e Habilitação como Professor Titular (FSP/USP, 1995). MA em Antropologia (Universidade de Wisconsin, Madison, 1968); Sanitarista (FSP/USP, 1971). Bacharel em Ciência Sociais (FESP/SP, 1963) e Direito (PUC/SP, 1996). Linhas de pesquisa e publicações principais nos temas: migração internacional, nupcialidade/casamento, fecundidade, família. 
